\title{
CAPITAL AND TIME: VARIATIONS ON A HICKSIAN THEME
}

\author{
Peter Lewin
}

\section{INTRODUCTION}

John Hicks has written extensively on capital. In addition to his three very influential books which have capital in their titles $(1946,1965,1973 b)$ he has published numerous articles. He was a scholar who returned many times in his life to the same questions, sometimes with different answers. ${ }^{1}$ In Value and Capital (1946, first edition 1939) he critically considered Böhm-Bawerk's average period of production. His Capital and Growth (1965) was a series of exercises in growth theory. But, as with all of Hicks's work, this book contains much discussion of an informal nature. These extended discussions show that he was thinking carefully about the implications of time for the theory of capital. We see it in his introductory remarks on methodology, particularly his discussion of equilibrium; we see it in his survey models of Smith and Ricardo and we see it in his concern about how to portray the transition from one equilibrium steady state growth to another, the problem of the 'traverse'. And then in a series of contributions in the 1970's, including his book Capital and Time (1973b, also 1976, 1979a and 1979b), he becomes very concerned with time as a topic in economics. Along with this concern came a revived interest in the Austrian theory of capital.

Hicks called his new approach to capital a Neo Austrian approach. This label does not seem to have been auspicious for the acceptance of his approach. The modern Austrians did not embrace it (Lachmann 1973), and the mathematical Böhm-Bawerkians (Faber 1979) criticized it for other reasons. In this paper I reexamine this new approach. I find that it is quite revealing in a way that perhaps Hicks himself did not fully realize. Many of the traditional issues in capital theory come together nicely in Hicks's final treatment.

\section{HICKS AND TIME}

Hicks had an abiding interest in and a fascination with the implications for economics of the passage of time. His treatment is ambiguous however. Hicks's attitude to time parallels in many ways his relationship to the Austrians (particularly of the market process variety) and the radical subjectivists. Few economists have been more influential. Yet few defy categorization as he did. He was at once Keynesian, Neoclassical and in his verbal remarks, if not in his formal models, he made important concessions to the Austrians. His critics thus had an easy target, being able to find numerous inconsistencies. From the one side he was criticized for being too formal and mechanistic. From the other he faced technical challenges to his formal models. He continually walked a tightrope.

\footnotetext{
"'Capital (I am not the first to discover) is a very large subject, with many aspects; wherever one starts, it is hard to bring more than a few of them into view. It is just as if one were making pictures of a building; though it is the same building, it looks quite different from different angles. As I now realize, I have been walking round my subject, taking different views of it" (Hicks 1973b, p. v).
} 
We see this in his treatment of time. He believed in the importance of the "irreversibility of time". Time was not strictly analogous to space. Concerning this realization he says: "I have not always been faithful to it, but when I have departed from it I have found myself coming back to it" (1976, p. 263). One cannot escape the fact that the future is not determined in the same way as the past is. "How easy it is [however] to forget, when we contemplate the past, that much of what is now past was then future". This has profound implications for the meaning of any time series. "Action is always directed towards the future; but past actions when we contemplate them in their places in the stream of past events, lose their orientation toward the future which they undoubtedly possessed at the time when they were taken. We arrange past data in time-series, but our time series are not fully in time. The relation of year 9 to year 10 looks like its relation to year 8 ; but in year 9 year10 was future while year 8 was past. The actions of year 9 were based, or could be based, upon knowledge of year 8; but not on knowledge of year 10, only on guesses about year 10. For in year 9 the knowledge that we have about year 10 did not yet exist (Ibid., p. 264, italics added)."

One of the far reaching implications of this concerns the theory of capital. Consider changes in the value of the capital stock. "The value that is set upon the opening stock depends in part upon the value which is expected, at the beginning of the year, for the closing stock; but that was then the future, while at the end of the year it is already present (or past). There may be things which were included in the opening stock because, in the light of information then available, they seemed to be valuable; but at the end of the year it is clear that they are not valuable, so they have to be excluded. This may well mean that the net investment of year 1, calculated at the end of year 1, was over-valued - at least it seems to be over-valued from the standpoint of year 2" (Ibid., p. 265).

We see here much with which Lachmann, for example, would agree. And similar statements are to be found throughout Hicks's work, particularly in this latter period. Yet when he reviewed Hicks's Capital and Time Lachmann focused critically on Hicks's more formal 'out of time' analysis (Lachmann 1973). Lachmann all but ignores the potential of the first two chapters and much of Part III for a more subjectivist approach, one that incorporates aspects of the connection between time and knowledge that he had worked out. ${ }^{2}$ In what follows I examine the essentials of Hicks's conceptual framework (from Capital and Time) and attempt to draw out some of the implications and insights that emerge when interpreted from a subjectivist point of view. This framework is a convenient and efficient organizing device in which all of the various influences on the capital formation process come together.

\section{A SIMPLE CONCEPTUAL FRAMEWORK}

\footnotetext{
${ }^{2}$ It is clear that Hicks was sensitive to Lachmann's criticisms:
}

Most of my critics have been ... equilibrists; but there is one, for whom I have the greatest respect, who has opened fire from the other flank. Professor Ludwig Lachmann, ... is (like Professor Hayek) a chief survivor of what I distinguished as the Mengerian sect of the Austrian school. It is clear that his view of me is like Menger's view of Böhm Bawerk. He cannot of course abide the steady state. Even the modest uses of it which I have made ... fill him with dismay. Even the explanations which I have now been giving (and which are meant, incidentally, to assure him that I am more on his side than on the other) will, I fear, fail to placate him. His ideal economics is not so far away from my own ideal economics, but I regard it as a target set up from heaven. We cannot hope to reach it; but we must just get as near as we can (Hicks 1976, p. 275, footnote omitted). 
Hicks begins by noting the different kinds of capital and different kinds of capital processes in which they are found.

There are different theories of capital because there are varieties of capital. The capital, the real capital, of any economy extends the whole way from very durable instruments - almost land, and some would say that land itself should be included - to goods that are in the pipeline, goods in process of production (Hicks 1973a, p. 97).

The old Austrian theory (of Menger and the Mengerian elements of Böhm-Bawerk) is a 'goods in the pipeline approach' while the production function approaches are of 'a quasi land, fixed capital' variety. A satisfactory theory of capital should be able to encompass both. Böhm-Bawerk's attempt to capture Menger's vision used a flow-input-point-output approach and Wicksell extended this to a pointinput-point-output (aging wine) approach. These models are models of time. They characterize the production process in terms of time (or, as in the case of Wicksell, in terms of a capital quantity derived using time units - quantities of dated inputs). Hicks is concerned to provide a theory of capital that is in time. Such a theory would have to be a flow-output theory.

Goods that are produced by the use of fixed capital are jointly supplied. It is the same capital good which is the source of the whole stream off outputs - outputs at different dates (Ibid., p. 98).

If it were not for joint supply we could, on the whole, get on very well with a cost of production theory of value. So it is here. If it were not for the joint supply that is implied in the use of fixed capital, we could get on very well with the Böhm-Bawerkian model, in which we associated with every unit of final output a sequence of previous inputs which have 'led to' that output; so that the cost of the final output is representable as a sum of the costs of the associated inputs, accumulated for each by interest for the appropriate length of time. In an economy which uses fixed capital such imputation is not possible (Ibid., p. 99). ${ }^{3}$

So Hicks proposes the abandonment of the 'period of production' approach. There is no measure of roundaboutness.

What we must not abandon are Böhm-Bawerk's (and Menger's) true insights - the things that are the strength of the Austrian approach. Production is a process in time....the characteristic form of production is a sequence, in which inputs are followed by outputs. Capital is an expression of sequential production. Production has a time structure so capital has a time structure (Ibid., p. 100).

Thus, we define a production process as a stream of inputs, giving rise to a stream of outputs. A production process may be thought of also as a technique (for converting inputs into outputs) or a project. It may take many concrete forms, like the building of a factory, or the construction of a machine, or the exploration for oil, etc. followed by the flow of a particular output (or set of outputs). Many (most? all?) production processes can be characterized in this way. Inputs and outputs are to be thought of in terms of value (or expected value), so outputs could be negative, but it is hardly conceivable that outputs should precede inputs at the start. Hicks asks a fundamental motivating question: "What, in general, are the conditions that must be satisfied in order that the process should be viable?" (Ibid., p. 100) ${ }^{4}$.

\footnotetext{
${ }^{3}$ In a footnote to this Hicks notes: "The point, it may be remarked..., is well understood by the intelligent accountant. $\mathrm{He}$ is well aware that in the case of products that are jointly supplied, the allocation of overhead costs is arbitrary; and he is also aware that the depreciation allowances which he makes are arbitrary, for they similarly involve an allocation of common costs to the jointly produced outputs at different dates" (Ibid., p. 99n).

${ }^{4}$ Interestingly he does not say "optimal." Of course the implication is that the producer will choose the highest capital value from among the imagined alternatives (given any scale of operation). But, as we shall note, in the
} 
Considered in this way the question can be answered by the use of some simple and familiar arithmetic which, though simple, has some important implications. We start by looking at the situation faced by the individual decision maker ex ante. So the input and output values are prospects. In this way we are attempting to uncover certain general principles that are implicit in any production plan.

Every process (or project) has a capital value (familiar as the net present value, NPV). This is the discounted flow of the sum of the net values yielded by the project over its life. Hicks shows that a necessary condition for the viability of any process as a whole is that its capital value should be positive (or at least non negative) at every stage in its life (Hicks 1973a, p. 17, 1973b, p. 100). In other words, the NPV should be positive whatever the date for which we make the calculation. The capitalized value of the output flow must always be at least as great as the capitalized value of the flow of inputs. If this were not the case then the process should be abandoned at the point at which the NPV ceased to be positive. At every stage in the life of the project the question of its continuation may be raised. At each point this is essentially an investment decision. So the project should not be continued if the value of what remains (the remainder) at any date, and as if contemplated from that date, is not positive (non negative). In other words, contemplated at the date of inception it is possible to calculate a capital value at each imagined future date in the life of the project. Each and every such capital value, as contemplated by the decision maker, must be non negative. If even one of them were negative that would indicate that the project should terminate at that date. In fact that defines the termination date.

While this general principle must be true as an implication of rational planning, as of the point in time of the decision, it may of course happen that in the execution (as distinct from the contemplation) of the project the capital value at some point before planned termination unexpectedly becomes negative. This does not imply that the project should be immediately abandoned (although in retrospect it would seem that it should not have been started). The principle of the irrelevance of sunk costs applies and one would have to consider it as a new project where the 'costs' of abandonment (long term contractual costs for example) have to be compared against the 'costs' of continuing. That is to say though one or more of the original capital values, including all of the original elements, may turn out to be negative, because historical flows are irrelevant the capital value as contemplated (recalculated) in the present may nevertheless be positive. Similarly the capital values at any point may during the execution of the project turn out to be unexpectedly high. Thus we may define a successful plan as one whose capital values turn out as expected (or better).

Of course present value criteria are well known and are implied in all discussions of capital. What Hicks makes explicit here is the way in which present value appraisals change over time, specifically over the life of the project. He addresses the intertemporal value structure of a project, the logic within a single human plan concerning the relationship of the capital values at various contemplated dates to one another. So when Lachmann asks: "What can we say about the firm's production plan in general and the pattern of use prescribed to its capital combination in it?" and answers, "We might say of course that the firm will act in such a manner as to maximize the present value of its expected future income stream, but such a description of the equilibrium of the firm is of very

execution, in the unfolding of the plan, unexpected outcomes will cause the capital values to deviate from their planned contemplated levels. The continued viability of a plan thus depends on the considerations under discussion, whether or not it is considered optimal from some point of view. And the composition of the capital stock at any point of time will reflect the unfolding of these plans. 
little use to us," (Lachmann 1986: 64) he may be underestimating the usefulness of thinking in terms of the influences on the (present) capital value of any plan.

Hicks examines other ways of evaluating capital projects. Each plan (or capital project) will have an implicit yield, better known as the internal rate of return (IRR). If the capitalization process is conducted using this rate then the initial value will be zero; it is the rate that causes the NPV at the inception date to be zero. If the same rate, the IRR, is used to calculate the capital values at all other dates, they will become positive, rise to a peak (or perhaps a series of peaks) and eventually fall again to zero at the termination point. Hicks also shows that for projects defined in this way the IRR is unique (Hicks 1973b: 22, but see footnote 7 below). The foregoing can be greatly clarified with some basic algebra.

\section{FORMALIZATION}

We denote input values and output values at time $t$ (contemplated at time 0 ) as $a_{t}$ and $b_{t}$. Also, $\mathrm{a}_{\mathrm{t}}=\sum_{\mathrm{i}} \mathrm{w}_{\mathrm{it}} \alpha_{\mathrm{it}}$, where $\mathrm{w}_{\mathrm{it}}$ is the price and $\alpha_{\mathrm{it}}$ is the quantity of input $\mathrm{i}$ at time $\mathrm{t}$, assuming a set of $(\mathrm{i}=1, \ldots$ $\mathrm{m}$ ) inputs. ${ }^{5}$ For convenience we will suppress the i subscript, assuming only one type of input, and write $a_{t}=w_{t} \alpha_{t}$ without loss of generality (alternatively $\alpha$ and $w$ may be thought of as vectors). Similarly, we write $b_{t}=p_{t} \beta_{t}$, where $p$ is the price and $\beta$ the quantity of the output. ${ }^{6}$ For convenience we define, $q_{t}=$ $b_{t}-a_{t}$, as the net output value at any date $t$. We denote the capital value at time $t$ by $k_{t}$.

$$
\begin{aligned}
\mathrm{k}_{\mathrm{t}}=\mathrm{q}_{\mathrm{t}} & +\mathrm{q}_{\mathrm{t}+1} \mathrm{R}^{-1}+\mathrm{q}_{\mathrm{t}+2} \mathrm{R}^{-2}+\ldots+\mathrm{q}_{\mathrm{n}} \mathrm{R}^{-(\mathrm{n}-\mathrm{t})} \\
& =\mathrm{q}_{\mathrm{t}}+\mathrm{R}^{-1} \mathrm{k}_{\mathrm{t}+1}=\left(\mathrm{b}_{\mathrm{t}}-\mathrm{a}_{\mathrm{t}}\right)+\mathrm{R}^{-1} \mathrm{k}_{\mathrm{t}+1}
\end{aligned}
$$

where $\mathrm{R}=1+\mathrm{r}$, and $\mathrm{r}$ is the per period rate of interest, or more accurately, rate of discount. This says that the capital value at the beginning of any subperiod $t\left(\mathrm{k}_{\mathrm{t}}\right)$, which is the discounted value of all of the remaining net outputs, can also be calculated as the net value of the output of that period $\left(q_{t}=b_{t}-a_{t}\right)$ plus the capital value of the remainder, for subperiods after $t, R^{-1} k_{t+1}$. And this holds for any value of $t$.

Hicks now offers what he calls the "Fundamental Theorem": it is always true that a fall in the rate of interest (rate of discount) will raise the capital value of any project throughout (that is as calculated at any date t), while a rise will lower it. The proof follows from equation (1) and it is instructive to reproduce it here at some length.

[S] uppose that the q's are unchanged but that $r$ falls, so that the discount factor rises. We see at once ... that $k_{t}$ is bound to rise, provided that $k_{t+1}$ is positive; and provided that $k_{t+1}$ is not reduced by the fall in interest. But a similar argument applies to $\mathrm{k}_{\mathrm{t}+1}$. Thus we may go on repeating, up to the end of the process, where $k_{n}=q_{n}$. Thus $k_{n}$ is unaffected by the fall in $r$; so $k_{n-1}$ must be raised, and therefore $k_{n-2}$ must be raised; and so on, back to $\mathrm{k}_{\mathrm{t}}$. So long as all the $\mathrm{k}_{\mathrm{t}}$ 's are positive (as we have seen that they must be, in order that the process should be viable), every $k_{t}(0$ to $n-1)$ must be raised by the fall in the rate of interest.

\footnotetext{
${ }^{5}$ One may think here of a production function like $Q_{t}=f\left(\alpha_{1 t}, \alpha_{2 t}, \ldots, \alpha_{m t}\right)$ at each point in time t. The meaning of the $\alpha_{i t}$ will depend on the context. Where we think of all factor inputs as reducible to the original inputs in a sort of 'macro' context then they are of the form of 'labor' and 'land'. Considered as a component of an individual production plan the $\alpha_{\text {it }}$ must include produced inputs, that is capital goods. See equation (4) in the text below.

${ }^{6}$ For a multiproduct firm, $\mathrm{b}_{\mathrm{t}=} \Sigma_{\mathrm{j}} \mathrm{p}_{\mathrm{j} t} \beta_{\mathrm{jt}}$, where $\mathrm{j}=1, \ldots, \mathrm{z}$ is the set of outputs.
} 
...We have taken it for granted that the duration of the process remains at $(n+1)$ weeks [subperiods], even though the rate of interest falls. But it is immediately clear that even if the duration is variable, it cannot be shortened. For since we have shown that with unchanged duration, every $\mathrm{k}_{\mathrm{t}}(\mathrm{t}<\mathrm{n})$ will be raised, it must still be advantageous to go on for at least the same duration, at a lower rate of interest. All that is possible is that the process may be lengthened.

But the process will only be lengthened if $k_{n+1}$ (which was zero at the higher rate of interest) becomes positive at the lower. That can happen, if the lengthening requires some net input (repairs, for instance, which only become profitable when the rate of interest falls). If it happens, however, all earlier $k_{t}$ must be raised, a fortiori. So the Theorem continues to hold when duration is variable (Hicks 1973b, pp. 20-21).

This characterization of a capital plan thus shows, in the first instance, how the planner's appraisal will be affected by changes in the discount rate he applies. But it is equally clear that this appraisal will depend on all of the other conditions that characterize the project. For example, if the prices of the inputs $w_{t}$ were to rise (or be expected to rise) the capital values would fall. Similarly a rise (expected rise) in the price of the product would raise all $k_{t}$. Changes in technology may affect these prices, by affecting processes elsewhere in the economy, or they may change the pattern of inputs, $\alpha_{t}$, required.

The value of $r$ for which $k_{0}=0$ is the IRR. This can be thought of as the yield of the project. It represents the minimum that would have to be earned on any alternative project if this one were to be abandoned in its favor. If 'wages' w were to rise (uniformly) all of the $k_{t}$ would be reduced. This implies that the yield of the project, its IRR, would fall. Thus for a given project (or set of projects) there is a trade off between changes in $\mathrm{w}$ and $\mathrm{r}$, other things constant. This is the sense in which the Neo Ricardians perceive the existence of a 'factor price frontier' defining different equilibrium distributions of income between the factors of production. Considering hypothetical changes in $\mathrm{w}$ and changes in $\mathrm{r}$ necessary to 'compensate' for these changes (by keeping $\mathrm{k}_{0}=0$ ), one can imagine situations in which one technique, while dominant at a given level of $r$, loses its dominance as $r$ falls and then regains it again as $r$ continues to fall with rises in $w$. The significance of this hypothetical tradeoff is far from clear however, given that any pattern of inputs $\alpha_{t}$ is, in principle, possible. Also, there is no unambiguous way in which we can decide which project, or technique, is more 'capital intensive'.

Moreover, it is important to note that in the context we have developed above, $\mathrm{r}$ cannot be taken to be the price or rate of earnings (profits) of capital. $\mathrm{r}$ is the rate of discount applied to the overall earnings of the project at different dates. In fact the identification of $w$ as 'wages' is a simplification that assumes that all of the inputs are reducible to labor. Had we wished, we could have included produced means of production among the $\alpha_{t}$ inputs. None of our conclusions would be affected by this. $\mathrm{w}_{\mathrm{t}}$ would then refer to wages on labor and rents on capital goods.

\section{LOOKING FORWARD AND LOOKING BACKWARD}

It should be emphasized that this view of the capital process presented above is a forward looking one. All of the values are prospective. We may even think of each project as a capital prospect. As such there is an unavoidable, but often suppressed speculative element to it. There is at least one other possible way to look at capital processes in time, that is retrospectively, as a result of capital invested. From equation (1),

$$
\mathrm{k}_{0}=\mathrm{q}_{0}+\mathrm{q}_{1} \mathrm{R}^{-1}+\mathrm{q}_{2} \mathrm{R}^{-2}+\ldots+\mathrm{q}_{\mathrm{t}-1} \mathrm{R}^{-(\mathrm{t}-1)}+\mathrm{k}_{\mathrm{t}} \mathrm{R}^{-\mathrm{t}}
$$


for any value $t$ between 0 and $n$. Using the IRR in $R, k_{0}=0$, so,

$$
k_{t}=\left(-q_{0}\right) R^{t}+\left(-q_{1}\right) R^{t-1}+\ldots+\left(-q_{t-1}\right) R
$$

Looked at this way $\mathrm{k}_{\mathrm{t}}$ is the sum of the net inputs, $-\mathrm{q}=\mathrm{a}-\mathrm{b}$, from 0 to $\mathrm{t}-1$, accumulated by interest up to week $t$. This captures the idea of inputs maturing at a rate equal to the IRR and emerging as a final output.

For plans that are successful, in the sense that the capital values $\mathrm{k}_{\mathrm{t}}$ turn out to be exactly equal to what they were expected to be, when discounted or accumulated using the IRR, it should be clear that the two ways of looking at capital (prospective and retrospective) are exactly equivalent, they describe an ongoing and, in an essential sense, unchanging process. This is what the assumption of a steady state buys us, namely that the process, all processes, look the same at all points of time and for all points of time. In the steady state, since all plans are successful in this sense, the interest rate on loans must be equal to the (known) yield on projects, and the latter must be uniform (for any given investment period) across projects. We are in a Ricardian world.

We note in passing that the Neoclassical production function approach is a steady state approach in this sense. Write:

$$
\mathrm{Q}_{\mathrm{t}}=\mathrm{A}_{\mathrm{t}}(\mathrm{t}) \mathrm{f}\left(K_{\mathrm{t}}, L_{\mathrm{t}}\right) \quad \text { using time subscripts to indicate an ongoing process in time }
$$

or $\quad \mathrm{Q}_{\mathrm{t}}=\mathrm{A}_{\mathrm{t}-1}(\mathrm{t}) \mathrm{f}\left(K_{\mathrm{t}-1}, L_{\mathrm{t}-1}\right) \quad$ if we allow for time lags, where $\mathrm{Q}$ is output and $K$ and $L$ are inputs of capital and labor respectively.

We thus have an identical series of inputs (proportional to the stocks of factor of production) and outputs in every period t. Changes in the inputs will cause changes in the outputs once and for all. The process looks the same from all points of time.

Hicks is critical of the steady state:

I am very skeptical of the importance of such 'steady state' theory. The real world (perhaps fortunately) is not, and never is, in a steady state....A 'steady state' theory is out of time; but an Austrian theory is in time (Hicks 1973b, p. 109).

And he goes on to explain that a theory that is in time would have to take note of history, would have to include inherited history, including the inevitably less than optimal capital stock, as a 'cause' of subsequent events.

For a theory that is in time, perspective matters, things look very different from different points of time. Most specifically, any process with a yield that is greater than the market rate of interest on loans, which it would have to have to be undertaken in the first place, would have the property that the capital value measured forward (prospectively) will be greater than the backward (retrospective) measure. And this will be true even at point 0 where $k_{0}=0$ measured forward. This is a basic implication of rational planning. If a process is successfully being carried out, and if its yield is greater than the interest rate, a capital gain will accrue at each stage of the process. Surely this is the real meaning of profit. The existence of profit, in this sense, absolutely depends on a disequilibrium between the yield and the interest rate. And this can persist only if there is no steady state, if there is no uniform (zero by this definition) rate of profit. The existence of profits implies different (varying) expectations. 
Technical progress will imply that the yield on new processes (embodying the new knowledge) will be above that on old processes (those processes that do not). Old processes will, if there is enough time, be replaced by new ones. The capital stock, the stock of tangible things, will, at any point of time, reflect the accumulated results of passed gains in knowledge. Although this is inimical to the steady state everything that has been said above with regard to the characterization of projects, techniques, processes, that make up capital, remains valid.

Social accounting, however, can only be done consistently in a steady state. Out of the steady state (a limiting case of which is the Ricardian stationary state) it is strictly impossible to derive aggregate values for capital and therefore for output (since the value of output depends on the value attributed to capital maintenance). Hicks explains this and then proceeds to assume a steady state in order to explore aspects of social accounting and transitions between such states. This, perhaps, is the reason for the less than warm reception that Lachmann accorded this work. Nevertheless his simple arithmetic framework reveals a lot even for those who believe that the market process should be analyzed as a disequilibrium phenomenon.

\section{CONCLUSION: CAPITAL PLANS AND MACROECONOMICS}

Hicks's framework presented above is a convenient way to think about capital. It is fully consistent with a modern Austrian approach as developed for example by Lachmann and Kirzner. According to this approach capital must be thought of in terms of intertemporal plans. We must make a distinction between capital goods and capital as an abstract category. The latter refers to the value to be attributed to a particular plan or set of production plans. The profits or losses to be attributed to a production plan are the result of changes (or the absence thereof) in the capital values attributed to it over time. These appreciations (or deprecations) in value are, in turn, the result of (are derived from) changes in consumers' evaluation of final production.

The meaning and the value of any particular capital good derives from its position in a particular production plan. 'The identification of a 'resource' as distinct from other physical things, cannot be made without reference to human purposes (Kirzner 1966, p. 38)". All capital goods are, in effect, an expression of "unfinished plans" (Ibid.: chapter 1). As such, these capital goods can be valued by what they add to the value of the plan. The value of any income source is derived from the income it is expected to produce; so the value of any capital good is familiarly thought of as being equal to the discounted value of the estimated income it adds to any production plan - the discounted value of its marginal product.

All production plans are affected by, among other things, changes in the rate of discount that is

pertinent to the plan. A fall in the discount rate will increase its value, a rise will decrease it. Thus if rates of discount are affected generally by macro economic changes, notably changes in interest rates, these may be expected to have a general effect on the expected value of existing and planned capital projects. In particular, those projects with the longest time horizon will be most affected. (This is well known and expressed in the proposition that the elasticity of present value is higher the higher the time horizon). Certain familiar macro economic scenarios thus follow from any general change in rates of discount that follow upon general changes in interest rates and (more importantly) expected interest rates. Thus, for example, producers perceiving a fall in the "social" rate of time preference (as translated in market rates of interest) will be led to the adoption of plans with longer time horizons as suggested by the Austrian theory of the business cycle. As explained, however, it is important to remember that the 
discount rate is only one of the variables that affects the capital values of any and all projects. Hicks's approach has the virtue of providing us with a particularly clear framework in which the various influences may be revealed. So we might write a general capital value (vector) function as

$$
\mathrm{k}_{\mathrm{t}}=\mathrm{k}_{\mathrm{t}}(\mathrm{w}, \alpha, \mathrm{p}, \beta, \mathrm{r}, \mathrm{n}) \text {, }
$$

indicating that $r$ is only one the determinants of $k$. $r$ is perhaps especially important because of its macroeconomic significance as the indicator of the relationship between present and future prices of consumption goods. However, the structure of prices and wages in general may affect the project (through $\mathrm{p}$ and $\mathrm{w}$ ) and technology obviously matters $(\alpha$ and $\beta$ ). Hicks approach gives a comprehensive picture.

\section{APPENDIX}

Hicks presents arguments for the existence and uniqueness of the IRR. Any viable process must be viable for $\mathrm{r}=0$, "if its inputs and outputs are undiscounted, its $\mathrm{k}_{0}$ must either be zero (in which case $\mathrm{r}=0$ is its internal rate of return) or it must be positive. But in the latter case, if the rate of interest rises ... $\mathrm{k}_{0}$ steadily diminishes, and must finally be reduced to zero - save in one special case ... when $\mathrm{b}_{0}-\mathrm{a}_{0}$ is positive (or zero)" which is a case of "production without capital". If $b_{0}-a_{0}$ is negative, and $k_{1}$ is positive (as it must be if $k_{0}$ is not to be negative), it is inevitable that

$$
\mathrm{k}_{0}=\mathrm{b}_{0}-\mathrm{a}_{0}+\mathrm{R}^{-1} \mathrm{k}_{1}
$$

should ultimately be reduced to zero by a rise in the rate of interest. So an IRR exists. The IRR is unique because the Fundamental Theorem applies as much to $\mathrm{k}_{0}$ as to any other $\mathrm{k}_{\mathrm{t}}$. "If we start from a rate of interest which is such that $\mathrm{k}_{0}$ is zero (the other k's being positive), any reduction in the rate of interest must increase $\mathrm{k}_{0}$. So $\mathrm{k}_{0}$ cannot be zero again at any lower rate of interest" (Hicks 1973a, pp. 140 and 140n).

It seems that Hicks obtains this result because of the way he defines a project as a series of positive yields over time (for each period except the first). Thus a negative yield (positive outlay) can be used to demarcate the start of a new project. From a more general perspective the IRR need not be unique. From

$$
\begin{array}{ll} 
& \mathrm{k}_{\mathrm{t}}=\mathrm{q}_{0}+\mathrm{q}_{1} \mathrm{R}^{-1}+\mathrm{q}_{0} \mathrm{R}^{-2}+\ldots+\mathrm{q}_{\mathrm{n}} \mathrm{R}^{-\mathrm{n}}=0 \\
& =\sum_{i=0}^{n} \mathrm{q}_{\mathrm{i}} \mathrm{R}^{-\mathrm{i}}=0 \\
\text { get } \quad & \mathrm{R}^{\mathrm{n}} \mathrm{k}_{\mathrm{t}}=\sum_{i=0}^{n} \mathrm{q}_{\mathrm{i}} \mathrm{R}^{\mathrm{n}-\mathrm{i}}=\sum_{i=0}^{n} \mathrm{q}_{\mathrm{n}-\mathrm{i}} \mathrm{R}^{\mathrm{i}}=0 \\
\text { or } \quad & 0=\mathrm{q}_{\mathrm{n}}+\mathrm{q}_{\mathrm{n}-\mathrm{1}} \mathrm{R}+\mathrm{q}_{\mathrm{n}-2} \mathrm{R}^{2}+\ldots \mathrm{q}_{0} \mathrm{R}^{\mathrm{n}} .
\end{array}
$$

The last line can be written,

$$
0=Q_{n}+Q_{n-1} r+Q_{n-2} r^{2}+\ldots Q_{0} r^{n}
$$

Where the $Q_{i}$ are linear combinations of the $q_{i}$ and $r$, and, it will be remembered $R=(1+r)$. Equation (5) is an nth order polynomial, with the roots equal to the IRR(s). Generally there will be more than one root, the number of roots will be equal to the number of changes in sign of the coefficients $\left(Q_{i}\right)$ at most (I owe this approach to the lecture notes of Professor L Sjaastad of the University of Chicago). Since Hicks has assumed one change in sign there is only one IRR.

The use of an IRR is at bottom a matter of convention. It depends not only on how one divides up a project over time, but also on assuming that the "internal" yield is the same for each subperiod. It seems intuitively clear, however, that the individual planner must have in mind some benchmark against which to (subjectively) test the 
attractiveness of a project in comparison, for example, with investing in the market. Each planner will define his own boundaries.

\section{ACKNOWLEDGEMENT}

I am indebted to the perceptive remarks of an anonymous referee.

\section{REFERENCES}

Faber, M. 1979. Introduction to Modern Austrian Capital Theory. New York: Springer-Verlag.

Hicks J.R. 1946 Value and Capital. Oxford: Clarendon Press. (2nd. edition). 1965. Capital and Growth. Oxford: Clarendon Press. 1973a. "The Austrian Theory of Capital and its Rebirth in Modern Economics." in Carl Menger and the Austrian School of Economics. Oxford: Clarendon Press. 1973. Reprinted in Hicks 1983, pp. 96102.

1973b. Capital and Time. Oxford: Clarendon Press. . 1976. "Some Questions of Time in Economics." in Evolution, Welfare and Time in Economics, Festschrift in honor of Nicholas Georgescu-Roegen. Edited by A. M. Tang et. al. Lexington: Lexington Books. 1976. Reprinted in Hicks 1984, pp.263-280. . 1979a. Causality in Economics. Oxford: Basil Blackwell. . 1979b. "Is Interest the Price of a Factor of Production?" in Time, Uncertainty and Disequilibrium. Edited by Mario Rizzo. Lexington: Lexington Books. 1979. Reprinted in Hicks 1983, pp. 113-138. . 1983. Classics and Moderns: Collected Essays on Economic Theory, Volume III. . 1984. The Economics of John Hicks. Selected and with an introduction by Dieter Helm. Oxford: Basil Blackwell.

Kirzner I. M. 1966. An Essay on Capital. New York: Augustus M. Kelly.

Lachmann L.M. 1973 "Sir John Hicks as a Neo Austrian." South African Journal of Economics. 41. September, pp. 195-207. . 1986. The Market as an Economic Process Oxford: Basil Blackwell. 